\title{
Pressure controlled vs. volume controlled ventilation during prone position in high-level spinal cord injury patients: a preliminary study
}

\author{
Mirum Kim ${ }^{1}$, Jieun Kim${ }^{1}$, Song Hwa Kwon ${ }^{2}$, and Gunn-Hee Kim ${ }^{1}$ \\ ${ }^{1}$ Department Anesthesioloy and Pain Medicine, National Medical Center, ${ }^{2}$ Department of Mathematics, The Catholic University of \\ Korea, Seoul, Korea
}

Prone positioning during operation is associated with significant challenges to anesthesiologists. Wilson Frame was introduced to reduce abdominal pressures. However, when it is applied inappropriately, it can increase peak airway pressure (PIP) and decrease dynamic compliance (Cdyn) by compromising the diaphragm movement [1].

Spinal cord injury (SCI) patients have a probability to get pressure sore operations in prone position under general anesthesia. Patients with quadriplegia have decreased chest wall and lung compliance, increased abdominal wall compliance. Their rib cage stiffness and paradoxical chest wall movements also result in an increase in the work of breathing. Expiratory muscle function is more compromised than inspiratory muscle function among subjects with quadriplegia and high paraplegia, which can result in ineffective coughing, accumulation of mucus and atelectasis. Vagal activity is high and baseline airway caliber is reduced in patients with quadriplegia [2]. Pulmonary function in SCI is compromised by most lesions of the spinal cord, even in those with paraplegia [3].

Therefore, it is questionable which ventilator mode is more effective on systemic oxygenation and safer during prone position in these patients, but these issues have not been well established. We are to investigate which ventilation method is effective to decrease peak inspiratory pressure (PIP) and to maintain systemic oxygenation.

This study was performed from January 2013 to March 2014.
After obtaining the Institutional Review Board's approval (IRB No. H-1302/027-001), 20 adult patients scheduled for debridement under general anesthesia were enrolled in this study. Patients who were neurologically stable SCI patients (quadriplegia and high level [above T4] paraplegia) for more than 2 years were included. Patients who were older than 75 years, or had severe pulmonary disease were excluded. Patients were randomized to either volume-controlled ventilation $(\mathrm{VCV}, \mathrm{n}=9)$ or pressurecontrolled ventilation (PCV, $\mathrm{n}=9$ ) group.

Patients were not premedicated. Patients were applied noninvasive blood pressure cuff, electrocardiogram, pulse oximetry in the operating room. General anesthesia was induced with 40 $\mathrm{mg}$ lidocaine, $1.5 \mathrm{mg} / \mathrm{kg}$ propofol, and $0.5 \mathrm{mg} / \mathrm{kg}$ rocuronium. After tracheal intubation with plain endotracheal tube, anesthesia was maintained with 0.8 to 1.2 vol\% sevoflurane in $\mathrm{N}_{2} \mathrm{O}$ and oxygen $\left(\mathrm{FIO}_{2}=0.5\right)$. Patient's lung was ventilated as follows; VCV group ventilated $10 \mathrm{ml} / \mathrm{IBW}$ (ideal body weight) and PCV group ventilated at PIP adjusted to same tidal volume with VCV group. Thirty minutes after induction, arterial $\mathrm{PaO}_{2}$, mean blood pressure (MBP), heart rate (HR), peak inspiratory pressure (PIP), mean inspiratory pressure (Pmean), respiratory rate (RR) and expired tidal volume $\left(\mathrm{V}_{\mathrm{T}}\right)$ were recorded. Then, patient position was changed to prone and the same procedure was repeated as above.

Statistical analyses were performed with SPSS 16.0 (SPSS Inc., Chicago, IL). Data were presented as means \pm SD or number of

Corresponding author: Gunn-Hee Kim, M.D., Ph.D., Department Anesthesioloy and Pain Medicine, National Medical Center, 245, Eulji-ro, Jung-gu, Seoul 100-799, Korea. Tel: 82-2-2260-7372, Fax: 82-2-2260-7142, E-mail: ipsse@dreamwiz.com

(c) This is an open-access article distributed under the terms of the Creative Commons Attribution Non-Commercial License (http:// creativecommons.org/licenses/by-nc/3.0/), which permits unrestricted non-commercial use, distribution, and reproduction in any medium, provided the original work is properly cited. 
Table 1. Mean Values of Intraoperative Variables

\begin{tabular}{|c|c|c|c|c|}
\hline & \multicolumn{2}{|c|}{$\operatorname{VCV}(n=9)$} & \multicolumn{2}{|c|}{$\operatorname{PCV}(n=9)$} \\
\hline & Supine & Prone & Supine & Prone \\
\hline $\mathrm{V}_{\mathrm{T}}(\mathrm{ml})$ & $667.4 \pm 77.6$ & $674.2 \pm 82.1$ & $652.4 \pm 63.1$ & $652.4 \pm 63.1$ \\
\hline $\mathrm{PIP}\left(\mathrm{cmH}_{2} \mathrm{O}\right)$ & $15.1 \pm 3.4$ & $\begin{array}{l}19.4 \pm 4.4^{*} \\
(\mathrm{P}=0.001)\end{array}$ & $\begin{array}{l}13.3 \pm 3.4^{\dagger} \\
(\mathrm{P}=0.014)\end{array}$ & $\begin{array}{c}17.1 \pm 5.5^{*, \dagger} \\
(\mathrm{P}=0.001)(\mathrm{P}=0.043)\end{array}$ \\
\hline Pmean $\left(\mathrm{cmH}_{2} \mathrm{O}\right)$ & $4.2 \pm 0.9$ & $4.6 \pm 0.8$ & $4.8 \pm 1.5$ & $5.3 \pm 1.0$ \\
\hline $\mathrm{ETCO}_{2}(\mathrm{mmHg})$ & $34.6 \pm 1.3$ & $33.8 \pm 1.4$ & $33.7 \pm 1.5$ & $32.9 \pm 0.6$ \\
\hline $\mathrm{PaO}_{2}(\mathrm{~mm} \mathrm{Hg})$ & $349.5 \pm 98.7$ & $\begin{array}{c}279.9 \pm 106.5^{*} \\
(\mathrm{P}=0.001)\end{array}$ & $347 \pm 90$ & $\begin{array}{r}217.5 \pm 60^{*} \\
(\mathrm{P}=0.002)\end{array}$ \\
\hline RR (breaths/min) & $9.9 \pm 0.9$ & $\begin{array}{c}8.3 \pm 1.3^{*} \\
(\mathrm{P}=0.005)\end{array}$ & $9.7 \pm 1.3$ & $\begin{array}{r}7.9 \pm 1.2^{*} \\
(\mathrm{P}=0.009)\end{array}$ \\
\hline MV (L/min) & $6.4 \pm 1.0$ & $\begin{array}{c}5.6 \pm 0.6^{*} \\
(\mathrm{P}=0.017)\end{array}$ & $6.2 \pm 1.6$ & $\begin{array}{l}5.2 \pm 0.9 \\
(\mathrm{P}=0.05)\end{array}$ \\
\hline $\operatorname{Cdyn}\left(\mathrm{ml} / \mathrm{cmH}_{2} \mathrm{O}\right)$ & $46.6 \pm 13$ & $\begin{array}{l}36.4 \pm 10.1^{*} \\
(\mathrm{P}<0.001)\end{array}$ & $\begin{array}{l}51.5 \pm 12.2^{\dagger} \\
(\mathrm{P}=0.039)\end{array}$ & $\begin{array}{l}39.8 \pm 10.5^{*} \\
(\mathrm{P}<0.001)\end{array}$ \\
\hline HR (beats/min) & $86 \pm 16.7$ & $89.8 \pm 9.5$ & $95 \pm 5.6$ & $90 \pm 14.2$ \\
\hline $\mathrm{MBP}(\mathrm{mmHg})$ & $79 \pm 13.4$ & $87.3 \pm 14.0$ & $85 \pm 10.5$ & $78 \pm 11.3$ \\
\hline
\end{tabular}

Values are means $\pm \mathrm{SD}$. Cdyn: dynamic compliance of the respiratory system, $\mathrm{ETCO}_{2}$ : end-tidal carbon dioxide tension, $\mathrm{MV}$ : minute volume, PCV: patients with pressure-controlled ventilation, Pmean: mean airway pressure, Ppeak: peak airway pressure, Prone: at 30 minutes after the prone positioning, RR: respiratory rate, Supine: after induction of anesthesia in the supine position, VCV: patients with volume-controlled ventilation, $\mathrm{V}_{\mathrm{T}}$ : tidal volume. $* \mathrm{P}<0.05$, compared with supine position within the group. ${ }^{\dagger} \mathrm{P}<0.05$, compared with VCV group.

patients. Data between VCV and PCV group were compared using a paired $t$ test after pairing patients. A $\mathrm{P}<0.05$ was considered statistically significant.

There were no statistical differences in age, body mass index, male-to female ratio, quadriplegia - to- high level paraplegia ratio, anesthesia time, and operation time between the two groups.

The PIP increased after prone positioning in both groups. PIP in PCV group was lower than in VCV group. The RR and Cdyn decreased after prone positioning in both groups. The $\mathrm{PaO}_{2}$ also decreased after prone positioning but $\mathrm{SpO}_{2}$ was maintained above $98 \%$ in all patients during the study. There were no statistical differences in MBP and HR in both groups (Table 1).

In the present study, ventilation in PCV mode decreased PIP more in the prone position, but this does not mean to improve systemic oxygenation. Although $\mathrm{SpO}_{2}$ was maintained over $98 \%$ during operation time, it is difficult to conclude that due to a decreased PIP, PCV mode is more beneficial in quadriplegia or high-level paraplegia patients.

We presumed that our SCI patients have decreased pulmonary function. There are several studies supporting this presumption [3-5]. Almenoff et al. [3] presented SCI/pulmonary function investigation, studying 165 male military veteran out- patients. They found statistically significant correlations of SCI level with forced vital capacity (FVC), forced expired volume in 1 second $\left(\mathrm{FEV}_{1}\right)$, and peak expiratory flow rate (PEFR). Linn et al. [4] reported that the higher the SCI level, the more decreased in percent predicted forced vital capacity (FVC \%). They investigated the relationship between SCI level and FVC \% with 455 patients. Especially in SCI patients above the T4 level, the FVC $\%$ presented below $80 \%$ of normal findings [5]. Since our study included quadriplegia or above T4 level paraplegia patients, it may be postulated that at least FVC \%, FEV1, and PEFR were decreased in our patients. Another limitation of this study is small sample size. For resolving this problem, we used pairing methods in which two patients in each group were paired according to age, height, weight, and spinal cord injury level. Since the data showed normal distribution, we could use a paired t-test. Further larger-scale studies to explore these issues will be required.

In conclusion, it is suggested that when high-level SCI patients are ventilated under general anesthesia in prone position, PCV may decrease PIP more than VCV but oxygenation effect seems to be similar in both ventilation.

\section{References}

1. Palmon SC, Kirsch JR, Depper JA, Toung TJ. The effect of the prone position on pulmonary mechanics is frame-dependent. Anesth Analg 1998; 87: 1175-80.

2. Schilero GJ, Spungen AM, Bauman WA, Radulovic M, Lesser M. Pulmonary function and spinal cord injury. Respir Physiol Neurobiol 
2009; 166: 129-41.

3. Almenoff PL, Spungen AM, Lesser M, Bauman WA. Pulmonary function survey in spinal cord injury: influences of smoking and level and completeness of injury. Lung 1995; 173: 297-306.

4. Linn WS, Spungen AM, Gong H Jr, Adkins RH, Bauman WA, Waters RL. Forced vital capacity in two large outpatient populations with chronic spinal cord injury. Spinal Cord 2001; 39: 263-8.

5. Schilero GJ, Radulovic M, Wecht JM, Spungen AM, Bauman WA, Lesser M. A center's experience: pulmonary function in spinal cord injury. Lung 2014; 192: 339-46. 